\title{
Impact of Social Media on Consumer Behaviour
}

\section{Amandeep Singh ${ }^{a}$, Taranjit Singh Vij ${ }^{b}$, Rajveer Kaur ${ }^{c}$, Daljeet Kaur ${ }^{d}$}

${ }^{a}$ Chitkara Business School, Chitkara University, Punjab, India.

${ }^{\text {b} G N A ~ B u s i n e s s ~ S c h o o l, ~ G N A ~ U n i v e r s i t y, ~ P h a g w a r a, ~ P u n j a b, ~ I n d i a . ~}$

${ }^{\mathrm{c}}$ GNA Business School, GNA University, Phagwara, Punjab, India.

${ }^{\mathrm{d} G N A}$ Business School, GNA University, Phagwara, Punjab, India.

Article History: Received: 11 January 2021; Accepted: 27 February 2021; Published online: 5 April 2021

\begin{abstract}
This paper encompasses the research studies done on the impact of social media on consumer behaviour. Social media is used by billions of people around the world and has fast become one of the defining technologies of our time. People are using various social media websites and because of that the entire marketing landscape is changing. Massive audience is available who are spending many hours a day using social media across the various platforms and are majorly involved in information processing, entertainment and social connection activities, it is not surprising that marketers have started utilising social media as a marketing channel. Companies now place considerable value on the way in which social media can be used to shape consumer's brand/product perception and influence their buying decision. Rather than focusing on short-term advertising through technology, companies are integrating social media mechanisms to enhance the relationship with consumers. Therefore, companies need to better understand the changing behaviour of consumers, in order to create mutual benefits from the use of social media. So, the research paper talks about what activities the consumer are involved in, how branding on social media is important and how it can help in marketing the goods/services. It also highlights how user generated content helps in marketing of a company and what will be the future of social media and areas the companies should focus on which will impact the consumers behaviour.
\end{abstract}

Keywords: Branding, Buying Decision, Consumer Behaviour, Social Media, User Generated Content.

\section{Introduction}

In 2020, there were 3.81 billion individuals effectively utilizing web-based media on the planet and this is an expansion of 9.2\% on a year on-a year premise from 2019(3.48 billion). Back in 2015, there were just 2.07 billion online media clients. Online media clients are currently spending a normal of 2 hours and 24 minutes out of every day (Chaffey Dave 2020).

Online media has changed the game for some enterprises and trains, including buyer practices. Customer conduct looks at how feelings, mentalities and inclinations influence the purchasing conduct of the buyers.

Web-based media has involved a significant situation as a specialized device. Individuals across the globe utilize online media to associate with others or associations. Around the world, individuals have begun utilizing web-based media, for example, Facebook, Twitter, Instagram, Snapchat and LinkedIn to share their encounters. As clients, they share item audits, data about an assistance, exhortation on food or wellbeing, admonitions about items, tips on utilizing certain items, and substantially more. Individuals have a great deal of 'associations' via online media, along these lines data is devoured by numerous individuals. This data turns into a wellspring of effect on purchasers and effects their purchasing conduct.

Organizations regularly center around the most generally utilized online media stages for item showcasing and marking: Facebook, YouTube, Instagram and Twitter. Online media sites have gotten the focal point of data, appropriation of items, including the presentation of new product offerings, the making of brand mindfulness, and techniques to shape buyer conduct. Web-based media gives the remarkable chance to utilize informal promoting to a far reaching crowd, supporting buyer to-purchaser interchanges and expanding the brand mindfulness through a huge scope interpersonal organization.

The web-based media is engaging customers, and their job is moving from being uninvolved beneficiaries of data to turning out to be dynamic generators of data. With the gigantic premium in web-based media and usergenerated content (UGC) on destinations, for example, YouTube, Instagram, Snapchat, Facebook and twitter and so forth, shoppers are believed to be effectively adding to the promoting content. Customers are currently urged to interface with brands, share data with different purchasers and make their substance that reflects what their identity is, the thing that brands they incline toward and so on The more purchasers are occupied with this interaction, the more probable they are to urge others to investigate explicit brands. 


\section{Consumers and the Activities they are Involved in on Social Media}

Buyers have three primary delights or thought processes in utilizing the web as a medium, in particular, data, amusement, and social perspectives. (Shao 2009) recommended that individuals play out an assortment of exercises on the web: 1) Consumption of data and amusement, 2) support in social connection and local area advancement, and 3) creation of self-expression and self-actualization.

Utilization implies perusing the substance that is posted by different clients; investment happens when individuals remark on others' manifestations, and creation implies posting one's own substance on the site.

While, de Valck et al., (2009) recognized six distinctive virtual local area part types dependent on individuals correspondence or investment designs: 1) Core individuals were the individuals who added to the local area the most by recovering, providing, and examining data. 2) Conversationalists were the ones who zeroed in on examining data. 3) Informationalists fundamentally recovered and provided data. 4) Hobbyists zeroed in on keeping up and refreshing their own data on the site. 5) Functionalists were keen on recovering data. 6) Opportunists just recovered peripheral substance from the site. (This arrangement is subsequently founded on data exercises and did exclude different sorts of exercises). Table 1, Table 2, Table 3 are representing what activities consumers are involved in information processing, entertainment and social connection.

Table 1. Information Processing Activities

\begin{tabular}{|c|c|}
\hline Dimension & Description \\
\hline $\begin{array}{l}\text { Retrieving product information or } \\
\text { content }\end{array}$ & Acquiring information about products or download content \\
\hline Collecting factual information & $\begin{array}{l}\text { Gathering information from more formal user-generated sources, such } \\
\text { as Wikipedia. }\end{array}$ \\
\hline $\begin{array}{l}\text { Sharing and accessing opinions, } \\
\text { reviews and rating }\end{array}$ & $\begin{array}{l}\text { Sharing information and accessing shared knowledge online, such as } \\
\text { opinions and comments }\end{array}$ \\
\hline News surveillance & Following current news from all over the world \\
\hline Applying knowledge & $\begin{array}{l}\text { Using knowledge for own benefits, such as processing content or } \\
\text { exchanging products }\end{array}$ \\
\hline
\end{tabular}

(Source: Accessed from journal of consumer behaviour, Wiley online library)

Table 2. Entertainment Activities

\begin{tabular}{|l|l|}
\hline Dimension & Description \\
\hline Escaping the real world and relaxing & Relaxing or escaping for a while \\
Becoming inspired, mood management & Looking for inspiration and encouragement \\
Entertaining oneself & Enjoying oneself online \\
Self-expression & Self-articulation and self-promotion \\
\hline
\end{tabular}

(Source: Accessed from journal of consumer behaviour, Wiley online library) 
Table 3. Social Connection Activities

\begin{tabular}{|l|l|}
\hline Dimension & Description \\
\hline Social surveillance & Learning about friends and acquaintances \\
Belonging and bonding & Charing and experiencing with others \\
Being up-to-date & Knowing what is happening in one's own community \\
Staying in touch & Keeping up relationships within one's own network \\
Social networking & Creating and managing a social network of friends and acquaintances
\end{tabular}

(Source: Accessed from journal of consumer behaviour, Wiley online library)

\section{Consumer Activities Helping in Marketing of Products/ Services}

An investigation of Deloitte Touché' USA uncovered that $62 \%$ of US shoppers read buyer produced online surveys and $98 \%$ of them discover these audits sufficiently solid; $80 \%$ of these buyers said that perusing these audits has influenced their purchasing goals (Industry insights). Online media have changed showcasing by moving the adaptability of impact and the manners by which shoppers share, assess and pick data. With the ascent of webbased media, for example, websites, online discussions and interpersonal organizations the voice of the buyers has gotten more grounded and organizations understand that showcasing to the present innovation driven buyers mean taking part in two-manner correspondence. Web-based media is the new channel to obtain item data through friend correspondence. User-generated administrations assume a significant part in the passing on encounters and peerto-peer uphold. By sharing encounters and information, customers are making new types of administrations, which have a significant assignment in managing and coordinating dynamic of shoppers. Thus, purchasers read the surveys from various locales and get educated. The surveys can be positive or negative yet considers have demonstrated that positive audits probably won't muchly affect shopper purchasing choice yet even a limited quantity of negative data from a couple of postings can generously affect buyer demeanor towards the item/administration and this can spread a lot quicker after the occurrence 'turns into a web sensation'. Online gatherings effect and impact the conduct and the purchasing plan of a buyer. For instance, web-based media sites give a stage that gives singular shoppers their own voice, also admittance to item data that encourages their buy choices.

Numerous organizations today have pages via online media to enhance data held about items. Customers tend to relate substantially more with an organization after they read different surveys and remarks of different shoppers who have just bought these items. Besides, by utilizing web-based media, shoppers have the ability to impact different purchasers, through surveys. For instance, rather than purchasing an item that he knows practically nothing, customers have become new analysts. Prior to making a buy, numerous purchasers read other's opinion on a specific item by signing in, to a record on a web-based media webpage. Web-based media clients trust what their companions, family and even outsiders on these stages say. Numerous online purchasers think about these social destinations just like a significant and a dependable hotspot for investigating data regarding items and administrations.

A one-time buy or even recurrent acquisition of a similar item doesn't approach commitment with the client. It very well may be a proof that the client is happy with the item or administration yet even fulfillment and maintenance doesn't really connote client commitment. Drawn in clients are probably going to suggest items through websites, web-based media locales or verbal exchange such that they become promoters of the brand. They assist venders with understanding what their necessities are and contribute effectively in the item advancement measure. Through web-based media, associations can set up an exchange with existing and possible customers previously, during and after the exchange time frame with data, advancements and new item declarations. With the utilization of web-based media, advertising methodologies can turn out to be more tweaked and focused just as less expensive, quicker and more global in reach. Long range interpersonal communication has prompted the development of promoting from the advertising idea time to relationship showcasing period. The intuitive idea of online media empowers the foundation of discussions among people and organizations. This has 
come about organizations to attempt to all the more likely serve the clients and fulfill their necessities. Buyers utilize Social Media to communicate their reliability towards their \#1 brands and items.

Search through web-based media locales is on ascent as purchasers are going to web-based media channels for their data stage during dynamic cycle. Influencers inside the web-based media channels can altogether affect shopper conduct without having any immediate contact with the online client/guest.

Advertisers, for their organizations, produce content via online media (from this point forward named as advertiser created content (MGC) to connect with customers. Numerous specialists have reasoned that commitment in web-based media networks prompts a positive expansion in deals. Likewise, client produced content (UGC) and advertiser created content (MGC) through online media stages influence buyer conduct by giving them data and convincing them to purchase. Additionally, an enormous number of options choices is continually assessed by shoppers. Because of the commitment of customers and advertisers through web-based media, shoppers buy choices are regularly affected by both UGC and MGC and furthermore there is an increment in digitalised informal (WOM) correspondence. Advertisers are creating brand networks through online media stages to connect with buyers and produce WOM associations through data sharing which will uphold deals increment. Purchasers frequently prefer to share their item encounters about with individuals from a brand local area, communicating their fulfillment or disappointment. MGC may show a more fragile impact than that of UGC. As the purchasers have built up an inclination to doubt or be more wary towards showcasing messages. They feel that advertisers would utilize showcasing stunts to overstate the advantages of an item or limit weaknesses to convince customers to buy the item or administration. Additionally, shoppers will in general believe UGC in assessing items as customers feel that they have really evaluated the item and are giving fair audits. While big names like Selena Gomez are conceivable influencers for significant brands, these customary VIPs are costly to such an extent that more modest brands have started and will keep on benefiting from the prevalence and accomplishment of what are alluded to as "miniature influencers," addressing another type of influencers. Miniature influencers will be influencers who are not too known as VIPs, but rather who have solid and excited followings that are normally more focused on, producing anyplace between a couple thousand to a huge number of devotees (Main 2017). When all is said in done, these kinds of influencers are viewed as more reliable and valid than conventional big names by the customers, which is a significant explanation that influencer showcasing has become progressively engaging brands (Enberg 2018). These people are frequently seen as valid "specialists" in what they post about, urging others to buy what they like or believe is acceptable. Moreover, utilizing these influencers permits the brand to be hotter and more close to home and it has demonstrated to be more compelling in drawing in customers.

\section{Branding on Social Media and Online Buying Decision Model}

A brand can be characterized as "a name, image, sign, plan, or a term, or blend of them which is expected to distinguish the products and enterprises of one merchant or gathering of dealers and to separate them from those of contenders". Marking is frequently affected by social discernments, including the worth that people put on the brand and prevalent burdens, including the social messages that others put on brand possession. Customer conduct and decisions that they make are regularly determined by their impression of the brand and confidence in a brandbased encounter that is separated exclusively by acknowledgment of the brand. An individual may pick Starbucks not on the grounds that they offer the best support or the best espresso, but since they are a perceived brand that has related emotions, sensations, and insights.

Brand steadfastness turns into an expanding center when organizations consider the utilization of online media. While making a web-based media presence for a brand, the advancement of this sort of local area requires a comprehension of how online media functions and how brand networks' capacity. Brand people group are comprised of people who decide to take an interest and exhibit a relationship to the fundamental data, substance, or materials that are being partaken locally. This can remember discourse for items, reactions to new items, and techniques to make a social association that implies having a feeling of belongingness.

Not quite the same as the static (old) sites in the beginning of the Internet, the intuitive idea of online media has eventually changed the manners by which buyers draw in with brands. When utilizing online media consistently, purchasers are in contact with brands and items by perusing, composing, watching, remarking,

"Enjoying", sharing, and from multiple points of view. Specialists have shown that there are various devices incorporated into the online media stages that consider the making of a brand local area, the commitment of purchasers, electronic verbal, correspondence among peer gatherings, and client produced content, all of which upholds shopper commitment and make aggregate worth. 
As often as possible, brand worth and buying choices are connected more to the strength of friend interchanges and social systems supporting brand picture, instead of the firm-made substance accessible in promoting portions. These elements uphold the conviction that worth is lined up with brand mindfulness and these components hence impact how buyers react to a brand or item.

Indeed, even within the sight of changing web-based media components and the expanding utilization of innovation, customers actually experience a typical arrangement of steps in settling on choices that sway the buying choice. While figuring out what item to choose, "the customer initially procures information and mindfulness about an item, at that point builds up a good or a negative inclination towards the item lastly acts by purchasing and utilizing or by dismissing and staying away from the item". A shopper concludes if to buy it in the initial couple of moments of survey an item. The choice is additionally founded on the underlying acknowledgment of the brand. In the event that the shopper doesn't have a positive relationship with the remembering, they won't ever proceed onward to the following phase of dynamic.

The present purchasing conduct is frequently called online dynamic. Present day shoppers are assaulted with data each and every day over the Internet and their capacity to focus has decayed quickly. This implies that an average shopper's assessment cycle is fundamentally diminished from a phase of numerous days or hours to merely minutes or even seconds, which is significant for the advertisers to know, as the customary showcasing correspondence procedures don't work any longer (Ena 2017). The purchasers accomplish data about the item or administration effectively in light of the fact that it is accessible on the web and is effectively open.

The cutting edge purchaser's dynamic interaction is substantially more unique. It begins with the underlying thought and it is same as the conventional model which is started by need acknowledgment. It is trailed by data social affair and dynamic assessment of the other options. Web-based media and the Internet today, have permitted the buyer to approach data about the items and administrations on a worldwide scale. Through online media examination advertisers could screen post buy fulfillment. A fulfilled client isn't only prone to rehash the buy yet additionally share his positive perspectives about the brand in online journals and other web-based media stages that they are utilizing.

The purchasers can the read surveys and structure a mentality towards it, it tends to be an inspirational disposition or negative demeanor. On the off chance that it is uplifting demeanor, it will prompt buy choice and in the event that it is negative mentality, at that point they may search for some other option. What's more, after utilization on the off chance that he/she is content with his buy, he/she may give a positive audit which help in affecting others who are perusing or watching the surveys and on the off chance that he is disturbed, at that point it might prompt negative audit which the organization should deal with cautiously. Erasing negative remarks or input is an off-base activity as clients ought to be treated with deference and the brand's reaction ought to be moment. In the event that the post-buy period is appropriately upheld this could fabricate long haul brand devotion.

\section{What Social Media is and What will be its Future?}

As web-based media is developing, more extensive social ramifications will arise. To comprehend what will occur later on we need to grow our viewpoint. We need to see past the restricted open parts of online media and consider what will occur in the coming future (Lauren Grewal et al., 2019). Thus, we attempt to introduce what web-based media is and will become to have a more modern and more extensive viewpoint:

\subsection{Omni Social Presence}

As new patterns are arising, we can see that the customers are living in an "omni-social" world. From the advertising viewpoint, the buyer's dynamic cycle is influenced by online media impact and that is the "omni-social" nature of the current climate (Lauren Grewal et al., 2019). A shopper may distinguish a need when he/she watches their most loved influencer giving another item a shot YouTube/Reels. A buyer looking for a vehicle may request data to their companions on Facebook/Instagram with respect to what models they would suggest. A ravenous worker may check through Zomato audits to assess various alternatives to eat. An explorer may utilize Goibibo to book future convenience. At last, a client may yell about their experience (fulfilled or disappointed) of living in an inn on twitter.

Influencers are presently having their own TV shows/product offerings. Indeed, even the substance on TV, web arrangement and films are regularly intended to be "gifable" and image well disposed. "Made-for-Instagram exhibition halls" are empowering aesthetic substance and encounters that are uncommonly intended for selfietaking (Pardes 2017), (Lauren Grewal et al 2019). These models recommend that web-based media's impact is not 
really confined to the "on the web" world however is fairly reliably molding social antiquities (TV, film, expressions) that go past its conventional limits. We accept this pattern will keep on showing.

\subsection{Protection Concerns}

Each time somebody makes another online media account, they leave information drag along, as they give individual data that can incorporate their name, birth-date, topographical area and individual interests/diversions. Likewise, organizations gather client information to examine client conduct that is when, where and how clients interface. The entirety of this information is put away and utilized by organizations. They utilize this information to do target publicizing on clients. Some of the time, organizations offer clients' information to outsider substances, frequently without clients' information or assent. This is the reason shopper have issue with security via online media nowadays.

With disintegrating trust in web-based media stages and brands that publicize through them, numerous customers might not want to share information in any event, for more customized encounters, they are not happy with their buys being followed and they figure it ought to be illicit for brands to have the option to purchase their information.

In accordance with rising security concerns, the manner in which customers see brands and web-based media is getting progressively negative. Buyers are presently erasing their online media presence, research has indicated that almost $40 \%$ of carefully associated people confessed to erasing at any rate one web-based media account because of fears of their own information being misused (Edelman 2018),(Gil et al.2019).This is an adverse pattern for web-based media stages, however for the brands and publicists who have developed subject to these roads for arriving at buyers.

It's not just to the greatest advantage of online media stages to "improve" regarding policing content, yet the onus of obligation has been set on brands as well, to advocate for security, trust, and the evacuation of phony or derisive substance (Lauren Grewal et al., 2019).

\subsection{Battling Loneliness and Isolation}

Forlornness and disconnection are on ascent. In the course of the last numerous years dejection and disconnection rates have multiplied, with Generation $\mathrm{Z}$ to be considered as the loneliest age. A few scientists have discovered that online media impacts psychological well-being of clients. In particular, weighty online media use has been related with higher seen social seclusion, dejection, and sorrow. A few specialists have indicated that online media can profit people through various roads, for example, instructing and creating socialization abilities, permitting correspondence and approaching a more prominent asset of data and furthermore assisting with association and belongingness. A few analysts have demonstrated that online media doesn't affect mental prosperity.

Authoritatively talking, organizations are starting to react as a result of studies that are featuring a negative connection between online media and mental prosperity. For instance, Facebook has made "time restricting" apparatuses, even the versatile working frameworks, for example, iOS, likewise have these time-restricting highlights. One can restrict the warnings they get. They can likewise put their telephones on don't upset modes to stay away from any unsettling influences. Clients would now be able to check how long do they spend via webbased media and set up update cautions that spring up when a willful measure of time on the applications is hit. These various highlights are intended to attempt to give individuals a more certain online media experience. Regardless of whether these highlights will be utilized is obscure however they are truly useful in restricting our online media use.

\subsection{Incorporated Customer Care}

Client care through online media as we probably are aware will change soon. Until this point, numerous brands have utilized online media stages as a spot for giving client care, tending to clients' particular inquiries, fixing issues and tackling issues. Later via, web-based media-based client care is required to turn out to be considerably more modified and customized. Clients will have the option to draw in with firms without any problem. Also, the answers for clients' issues will be more open and quick, maybe we will utilize prescient methodologies (i.e., before a client even notification an issue or has an inquiry the appropriate responses will be given). 
Clients can message an organization, ask them inquiries through informing, which is regularly worked around chatbots and menial helpers. This training is relied upon to turn out to be more inescapable, particularly on the grounds that it places brands and organizations into the online media informing stages which their clients are as of now utilizing to speak with others, it gives snappier and moment reactions. It is financially adaptable using AIdriven chatbots and the utilization of chatbots can give a more customized level of client support.

We accept that later on, organizations will be capable perceive early signs of issues before clients themselves even acknowledge they are encountering an issue.

\subsection{Web-Based Media as a Political Tool}

Online media gives a stage to impart considerations and insights. This is particularly evident on account of conveying political conclusions. While web-based media isn't new to legislative issues, we accept that online media may play a lot bigger job as a political device in the middle future (Gil et al.2019). Proof of this could be found in the 2016 U.S. Official political decision. Online media took an alternate shape, with numerous endeavors to impact citizen's conclusions and contemplations. This is particularly valid for then-competitor and now-President Donald Trump. His utilization of Twitter pulled in a ton of consideration during the official mission and has kept on doing as such during his term in office. However, he isn't the only one, numerous lawmakers changed the manner in which they work and collaborate with individuals, with a new illustration of Congresswoman (chose US agent) Alexandria Ocasio-Cortez that even ran a workshop for individual congress individuals via online media.

While such stages take into account a quick dispersal of thoughts and ideas, there are a few, both in scholarly community and industry that have raised moral worries about utilizing online media for political purposes. Given that individuals pick who to follow, this specific conduct is said to conceivably make reverberation chambers, wherein, clients are presented distinctly to thoughts by similar individuals because of the calculation of web-based media applications/sites, showing expanded political homophily (Bakshy et al. 2015).

Individuals' inclination of having a gathering with similarly invested individuals isn't new. Social gatherings have been appeared to advance social distinguishing proof and elevate individuals who adjust to comparable thoughts. Moreover, it was likewise indicated that bunch individuals would emphatically disassociate and separate themselves from outgroup individuals.

In this way, it isn't unexpected to find that altered newsfeeds inside web-based media in light of the calculation. The issue is that online media shows news inclusion that is extraordinary to explicit clients, securing them their indicated reverberation chambers (Oremus 2016).

While online media stages concede that reverberation chambers could represent an issue, an answer isn't clear. One explanation that reverberation chambers are a particularly huge issue is a result of the phony news. Counterfeit news are created stories that attempt to camouflage themselves as bona fide content, to influence other web-based media clients (Gil et al.2019). Counterfeit news was generally utilized in the 2016 U.S. Presential races, with allegations that unfamiliar governments, for example, Iran and Russia, were utilizing bots to spread distorted substance assaulting Hillary Clinton and supporting President Trump.

Counterfeit news is on the ascent due to continued sharing of such news by bunch individuals. Redundancy of such articles by bots can just build the impact. Late exploration has indicated that in an apparent social setting, for example, web-based media, clients were less inclined to reality check data and furthermore dodged data that didn't fit well with their instinct (Schwarz and Newman 2017) Many specialists express that falsehood may be hard to address, particularly if the rectification isn't given quickly and the phony news has just sunk into the personalities of clients. It was likewise indicated that even a solitary phony news can make a drawn out impact on clients. It might change perspectives and assessments of the client.

Late exploration has indicated how the Chinese government deliberately utilizes a great many online remarks to divert the Chinese public from examining delicate issues and advance patriotism (King et al. 2017). Nowadays phony news utilizes a high level AI procedure called the Deep Fake is utilized to create fashioned pictures and recordings (which have all the earmarks of being genuine) of political pioneers while controlling what those pioneers say (Schwartz 2018). Such strategies can without much of a stretch numb-skull even the most keen client. Accordingly, research has started to investigate ways that web-based media stages can battle counterfeit news through calculations that decide the nature of shared substance (Gil et al.2019). 


\subsection{Expanded Sensory Richness}

A ton of new advances in the market are advancing and it causes us to foresee that the eventual fate of webbased media will be more tangible rich. One remarkable innovation that has just begun penetrating online media is enlarged reality (AR). Maybe the most well known illustration of AR is the Snapchat's channels, which utilizes a gadget camera to super force continuous visual or video overlays on individuals' appearances (counting highlights, for example, cosmetics, canine ears, and so forth) Other web-based media players immediately joined the AR trend, including Instagram's new appropriation of AR channels, Apple's Memoji informing and now AR channels are additionally accessible on androids as well. This probably addresses just a glimpse of something larger, especially given that Facebook, is one of the business' biggest financial specialists in AR innovation and has affirmed that it is chipping away at AR glasses (Lauren Grewal et.al 2019). Outstandingly, the organization intends to dispatch an engineer stage, so that individuals can construct increased reality includes that live inside Facebook, Instagram, Messenger and WhatsApp. The eventual fate of online media is probably going to look significantly more outwardly expanded. While AR and VR advancements bring visual lavishness, different improvements recommend that the fate of web-based media may likewise be more perceptible. Permitting clients to utilize web-based media in a sans hands and sans eyes way, this not just permits them to securely associate with web-based media while performing multiple tasks (especially when driving), however voice is additionally said to add a specific extravagance and credibility that is regularly absent from simple content based posts. Given that webcasts are more mainstream than any other time in recent memory and voice-based inquiry questions are the quickest developing portable hunt type, it appears to be likely that this correspondence methodology will appropriately appear more via online media as its utilization going ahead.

\subsection{Disconnected and Online Integration}

Presently there is a mix among on the web and disconnected procedures and we accept that later on we will go considerably further in obscuring the lines between what is disconnected and what is on the web, to build the viability of advertising advancements as well as to totally change the manner in which clients and organizations connect with one another. As referenced before, a striking innovation that has started penetrating online media is increased reality (AR). For instance, Ikea has been attempting to make an AR application that permits clients to take photographs of their space at home to precisely see what a household item would resemble in there, and this sort of innovation would likewise help in cosmetics, dress preliminaries as well. In this way, clients can evaluate stuff for all intents and purposes and on the off chance that they like it, they can get it.

\subsection{Web-Based Media Use by Non-Humans}

The clients of online media don't know whether they are associating with bots or with different people via webbased media sites, so there is a worry about the bot location as we don't become acquainted with who are we collaborating with. While a portion of these bots are supposed to be exceptionally useful and even valuable as they give data, they have additionally been appeared to disturb political talk, spread falsehood, and take individual data (Ferrara et al. 2016). These bots are an issue for online media clients as well as a major worry for advertisers. The organizations regularly realizes that an advertising effort was a triumph via online media with the assistance of measurements: Likes, Shares, Clicks, Comments, and Engagement rate. The presence of bots represents a developing danger to precise advertising and showcasing examination. Likewise, when these bots go about as "phony supporters," it expands the value of an influencer. This can likewise be utilized wrongly by people and firms; some influencers will buy "counterfeit" adherents to swell their online media reach. Web-based media has been typical for influencers to be paid for presents at rates proportionate on their supporter tallies, there have been issues to the game by having non-human "counterfeit" bot devotees.

In any case, there are preferences of having bots is that there is another classification of social bots who are acquiring expanding consideration. These are the treatment bots. These bots plan to help the psychological wellbeing of clients by proactively monitoring them, "tuning in" and visiting to clients whenever and prescribing exercises to improve their prosperity. Comparable bots are being utilized to "mentor/manage" the clients, and help them quit maladaptive practices, such as smoking. Curiously, by being non-human, these specialists/bots are seen to be less critical and along these lines, it very well may be simpler for clients to open up to them.

\section{Conclusion}

Web-based media has an enormous effect and a task to carry out in buyer's life. There are exercises that shoppers are associated with, via web-based media like data handling (i.e., understanding audits) that can help in framing discernment and mentality towards a brand/item/administration. Essentially, the diversion exercises may 
motivate them to make content via online media which will impact others to evaluate the items and social association exercises may prompt positive verbal. Thus, every action of purchasers via online media can be transformed into a chance by organizations to advertise their items/administrations.

The purchasing choice model has additionally been affected because of web-based media, presently shoppers can assemble data from web-based media by checking the surveys given by clients or miniature bloggers and likewise choose whether they need to purchase or not, likewise the post-buy conduct has been affected, if the customer is glad after the buy, he/she may prescribe the item to their supporters else they may show their lament on purchasing the item. Thus, the organizations need to deal with the grievances cautiously and attempt to determine the issue with purchasers. Something else, the negative survey may turn into a web sensation and this will affect the picture of the firm. Online media and the capacity of shoppers to counsel each other have changed the customary brand to customer relationship, placing the purchaser in a reasonable amazing position.

The paper additionally talks about, what online media is and will turn into, that it is inescapable that implies that it isn't simply virtual now it is changing our environmental factors and making it more amiable. Web-based media likewise has helped in fighting forlornness and confinement and in the event that an individual is abusing it, at that point there are numerous highlights given by various applications/sites today to control the utilization. Web-based media these days give a choice to shoppers to interface with the brand quickly to determine an inquiry or an issue. Also, it is being expected that in the coming future the innovation would be with the end goal that media would have the option to comprehend the inquiries, the shoppers may raise, in advance, on the grounds that media is constantly saving our information and is helping the organizations in doing prescient investigation. It additionally assists with persistent updates as respects to emotional wellness. The applications may speak with the buyer and keep a beware of them by tuning in, visiting and revealing to them different exercises that they can do to improve their prosperity. The media is additionally getting in AR and VR which will help a great deal of brands to grandstand items such that purchasers can attempt them practically.

It isn't generally that web-based media is acceptable, there are a few issues like individuals some way or another have a few issues with online media in regards to how their information is being sold for cash to outsider substances and they are not content with that, if the clients begin leaving web-based media because of protection concern, this may affect the brands since it has gotten a tremendous medium through which they speak with buyers. Additionally, web-based media spreads a ton of phony news which may change an individual's assessment on various things like legislative issues. Utilization of phony bots may affect the showcasing measurements which will prompt wrong expectations and friends would squander their cash

\section{References}

1. Akhunjonov, U., \& Obrenovic, B., (2017). Impact of Social Media on Consumer Buying Intention, Journal of International Business Research and Marketing, 3(1), 7-13.

2. Appel, G., Grewal, L., Hadi, R., \& Stephen, A.T. (2019). Future of Social Mediain Marketing, Journal of the Academy of Marketing Science,79-95.

3. Chaffey, D. (2016). Global social media research summary 2016. Smart Insights: Social Media Marketing.

4. Ena, F. (2017). The Impact of Social Media on Consumer Behaviour. Ligs University Blog Posts.

5. Gupta, M., Sahni, N.K., (2016). Consumer Behaviour, Kalyani publishers, New Delhi.

6. Heinonen Kristina, (2011). Consumer activity in social media: Managerial approaches to consumers' social media behavior. Journal of consumer behaviour, 356-364.

7. https://www.ligsuniversity.com/en/blogpost/the-impact-of-social-media-on-consumer-behavior

8. Ioanăs, E., \& Stoica, I. (2014). Social media and its impact on consumers behavior. International Journal of Economic Practices and Theories, 4(2), 295-303.

9. Kotler, P, (2017). Marketing Management, Prentice-Hall of India Private Limited, New Delhi.

10. Moustakas, E. (2015). Impact of Social Networking on Consumer Behaviour.

11. angi, P., Gupta, S.K., (2016). Business Research Methodology, Kalyani publishers, New Delhi

12. Singh, A., Singh, A., Taranjit, S.J., \& Pardesi, A. (2020). An empirical study of the factors affecting online shopping behavior of the indian consumers. International Journal of Advanced Science and Technology, 29(8s), 406-411.

13. Singh, A., Singla, B., \& Sharma, S. (2020). An Empirical Study of Factors Affecting the Selection of Point of Purchase Location: A Case of FMCG Industry. International Journal of Control and Automation, 13(2s), 72-78. 
14. Singh, A., Jain, A., \& Singla, B. (2019). Technological advancement-based paradigm shift: A focus shift from large screen to small screen. International Journal of Innovative Technology and Exploring Engineering, 8(10), 48-53. https://doi.org/10.35940/ijitee.I8613.0881019

15. Sonnartakki, C.N., Sharma, N., \& Gupta, A. (2015), Marketing management, Kalyani publishers, New Delhi. 